\title{
The early definitive internal fixation of complex pelvic fracture and its outcome: our experience in level 1 trauma care centre
}

\author{
Nitin Kimmatkar ${ }^{1}$, Kantharaju H. ${ }^{2 *}$ \\ ${ }^{1}$ Level 1 trauma center, Government Medical College, Nagpur, Maharashtra, India \\ ${ }^{2}$ Department of Orthopaedics, Government Medical College, Nagpur, Maharashtra, India
}

Received: 02 December 2021

Accepted: 03 February 2022

*Correspondence:

Dr. Kantharaju H.,

E-mail: kanthu1845@gmail.com

Copyright: (C) the author(s), publisher and licensee Medip Academy. This is an open-access article distributed under the terms of the Creative Commons Attribution Non-Commercial License, which permits unrestricted non-commercial use, distribution, and reproduction in any medium, provided the original work is properly cited.

\begin{abstract}
Background: Complex pelvic fractures have high mortality and morbidity hence required urgent resuscitation, haemodynamic stabilization and fracture fixation. Keeping in mind the various schools of thought regarding definitive management, there is need to study the outcomes of complex pelvic fractures after internal fixation surgery.

Methods: Twenty patients with complex pelvic fractures treated with internal fixation surgery in between $1^{\text {st }}$ June 2018 $31^{\text {st }}$ December 2019 with at least 12 months follow-up were included. Clinical and functional outcome of these patients was studied and evaluated using Majeed and Hannover scoring systems.

Results: Of 20 patients, 19 had closed while 1 had open pelvic fracture while 11 had tile type B and 9 had tile type C fracture. After 12 months of follow up, 72\% patients of tile B fractures and 55.6\% in tile $\mathrm{C}$ had excellent Majeed score with rest having good score. Hannover score was very good in $36.4 \%$ tile B cases and $22.2 \%$ tile $\mathrm{C}$ cases and good in $63.6 \%$ tile $\mathrm{B}$ cases and $77.8 \%$ tile $\mathrm{C}$ cases. Type of fracture (type $\mathrm{B}$ or type $\mathrm{C}$ ) had a statistically significant co-relation with chronic pain $(\mathrm{p}=0.016)$. It was also found that urogenital injury and sexual dysfunction $(\mathrm{p}=0.007)$ had a significant co-relation.

Conclusions: Early definitive internal fixation in patients with complex pelvic fracture had very good clinical and functional outcome. Most common associated injuries in complex pelvic fractures are urogenital injuries due to close proximity. In the outcomes chronic pain and sexual dysfunction are major issues. The sexual dysfunction patients usually associated fracture of pubic rami or pubic diastasis.
\end{abstract}

Keywords: Complex pelvic fracture, Functional outcome, Complications, Majeed score, Hannover score

\section{INTRODUCTION}

Complex pelvic fractures were combination of pelvic bone fracture, soft tissue injuries of pelvic region along with hemodynamic instability. ${ }^{1}$ The prevalence of these injuries constitutes about $1.5-3 \%$ of all skeletal injuries. ${ }^{2}$ They predominantly occurred due to high energy traumatic conditions like road traffic accidents, height energy fall and crush injuries. ${ }^{3}$ These fractures associated with high mortality $(30-50 \%)$ and morbidity rate. ${ }^{4,5}$ The rate of mortality is significantly increased by factors like haemorrhagic shock, open fracture and associated other systemic injuries. The management of complex pelvic fractures require a coordinated multidisciplinary approach from both pre-hospital trauma network and regional trauma centre team. It includes the early transportation with proper splintage, hemodynamic resuscitation, bleeding control and urgent stabilization of the pelvic ring. In recent time, evolution in diagnostic and therapeutic facilities resulted significant improvement in outcome. However, the management of these fractures is still challenging in developing world due to inadequate transport and health care facility. Majority of previous studies about complex pelvic fractures mainly were focused on the survival rate with least interest on outcome. In this study, we assessed the clinical, functional and social outcome of these fractures treated with early internal fixation surgery in our trauma centre. We hope that our 
study will help to increase the quality of treatment in terms of outcomes further reducing morbidity and mortality rate.

\section{METHODS}

In this retrospective observational study, we evaluated complex pelvic fracture patients treated by internal fixation in level 1 trauma care centre during $1^{\text {st }}$ June 2018 $31^{\text {st }}$ December 2019. The data was pooled out, patients were followed up. They were assessed with clinical and radiological examination and questioned in detail in the follow up for the study. The work was approved by institutional ethical committees and patients gave informed consent to work and data collected from them.

\section{Inclusion criteria}

Patients with open pelvic fracture or unstable pelvic fracture (type B and C tile classification), who underwent internal fixation with in 1-5 days of trauma and followed for a minimum of 12 months after internal fixation surgery were included in the study.

\section{Exclusion criteria}

Complex pelvic fracture patient with other comorbidities and only have external fixation as definitive treatment and patients non-compliant for follow-up were excluded from the study.

All patients are managed according to combination of extended focus assessment with sonography for trauma (EFAST) and institutional protocols (Figure 1). ${ }^{6}$ After initial resuscitation and stabilization of the patient, the fractures were classified according to Tile classification with help of pelvic plane radiograph and three-dimensional CT scan. ${ }^{7}$ After complete preoperative workup, all patients are operated within 1-5 days of trauma. Anterior column, pubic rami and symphysis were fixed using phannensteil incision with modified Stoppa dissection while posterior column, Crescent fractures, SI Joint and iliac blade were fixed by appropriate approach. In patients who were taken for emergency laparotomy for urogenital and bladder injury, definitive fixation was done in the same sitting. In such patients pubic rami and symphysis were fixed through the midline incision, used for laparotomy. To evaluate the outcome of complex pelvic fracture treatment, we used the Majeed functional score and Hannover score for polytrauma outcome (HASPOC). Majeed score assesses five factors, namely pain, standing, sitting, sexual activity, and working ability. ${ }^{8}$ Hannover score (HASPOC) is based on 2-part assessment including a subjective evaluation by a patient questionnaire and an objective evaluation by a physician after physical examination of the patient. $^{9}$ These scoring systems were chosen so that evaluation of clinical, functional and social outcomes from management of complex pelvic fracture can be accomplished. The complications like chronic pain, sexual dysfunction, and infection were also assessed and evaluated. The result was analysed with SPSS ver 20. All of the associations between the variables were analysed with Fischer exact test. The multi-variant analysis of complex pelvic fracture and comorbidities and functional score were analysed by logistic regression.

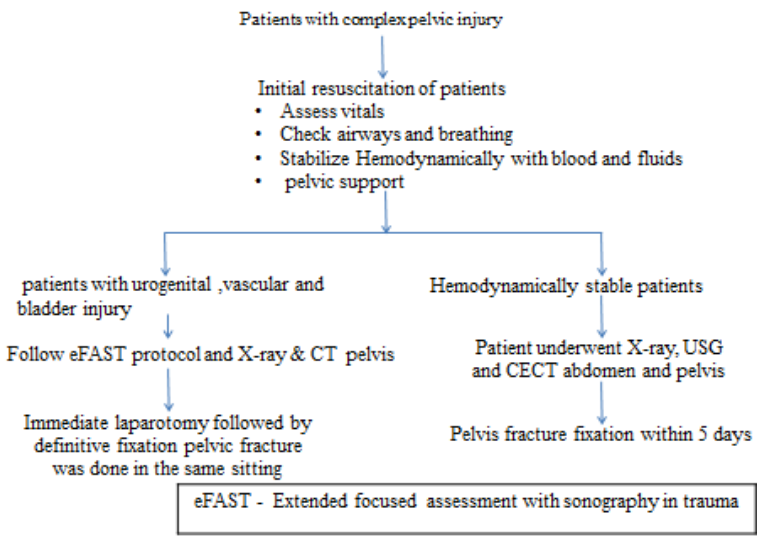

Figure 1: Institutional protocol for management of complex pelvic injury.

\section{RESULTS}

Patient demographic and injury data: Thirty-three complex pelvic fracture patients were admitted in our trauma centre during 2018-2019, of which 20 patients who fit the inclusion criteria were included in this study (Table 1). Average age was found to be $34.9 \pm 11.7$. Gender wise most patients were male $14(70 \%)$ while females were $6(30 \%)$. Age wise most patients were in the group of 20-40 years $(65 \%)$. Most of these fractures occur due to road traffic accidents $(75 \%)$. We had five cases $(25 \%)$ of complex pelvic fracture combined with fracture of other bone. Most of the complex pelvic fractures were accompanied with internal organ injuries (Table 2).

Table 1: Demographic characteristics.

\begin{tabular}{|l|l|}
\hline Characteristics & N $(\%)$ \\
\hline Age (Years) & \\
\hline$<20$ & $3(15)$ \\
\hline$>40$ & $4(20)$ \\
\hline $20-40$ & $13(65)$ \\
\hline Open or closed fracture & $1(5)$ \\
\hline Open & $19(95)$ \\
\hline Closed & \\
\hline Mode of injury & $15(75)$ \\
\hline road traffic accidents & $4(20)$ \\
\hline fall from height & $1(5)$ \\
\hline crush under heavy object & 11 \\
\hline Tile fracture type & 9 \\
\hline Tile B & 3.5 days \\
\hline Tile C & 10 days \\
\hline Average time for surgery & 14.2 month \\
\hline Average duration of stay in hospital & \\
\hline Mean duration of follow-up & \\
\hline
\end{tabular}


Table 2: Patients with associated injuries.

\begin{tabular}{|l|l|}
\hline Associated injuries & N $(\%)$ \\
\hline Urogenital injury & $9(45)$ \\
\hline Fracture in extremities & $6(30)$ \\
\hline Perineal rupture & $3(15)$ \\
\hline Head injury & $2(10)$ \\
\hline Abdominal injury & $2(10)$ \\
\hline
\end{tabular}

\section{Outcomes and complications}

In tile type $\mathrm{B}$ and type $\mathrm{C}$ fractures, excellent Majeed score were found on $72 \%$ and $55.6 \%$ cases respectively (Figure 2 ); while Hannover score was very good in $36.4 \%$ type B cases and $22.2 \%$ type $\mathrm{C}$ cases; and good in $63.6 \%$ type $\mathrm{B}$ cases and $77.8 \%$ type $C$ cases (Table 3 ). At the end of 12 months follow-up, Majeed score was excellent in $63.2 \%$ and good in $36.8 \%$ in closed fractures. Single open fracture case had excellent Majeed score and very good Hannover score. Sexual dysfunction (35\%) and chronic pain (35\%) were the most frequent complications observed followed by infection (20\%) (Table 4$)$. Sexual dysfunction occurred in 7 patients and all of them were males. Also, all sexual dysfunction patients had associated pubic rami fracture or pubic diastasis as a component of complex pelvic fracture. There were 2 non-union observed in our patients. Type of fracture (type B or type C) had a statistically significant co-relation with chronic pain $(\mathrm{p}=0.016)$. It was also found that urogenital injury and sexual dysfunction $(p=0.007)$ had a significant co-relation.

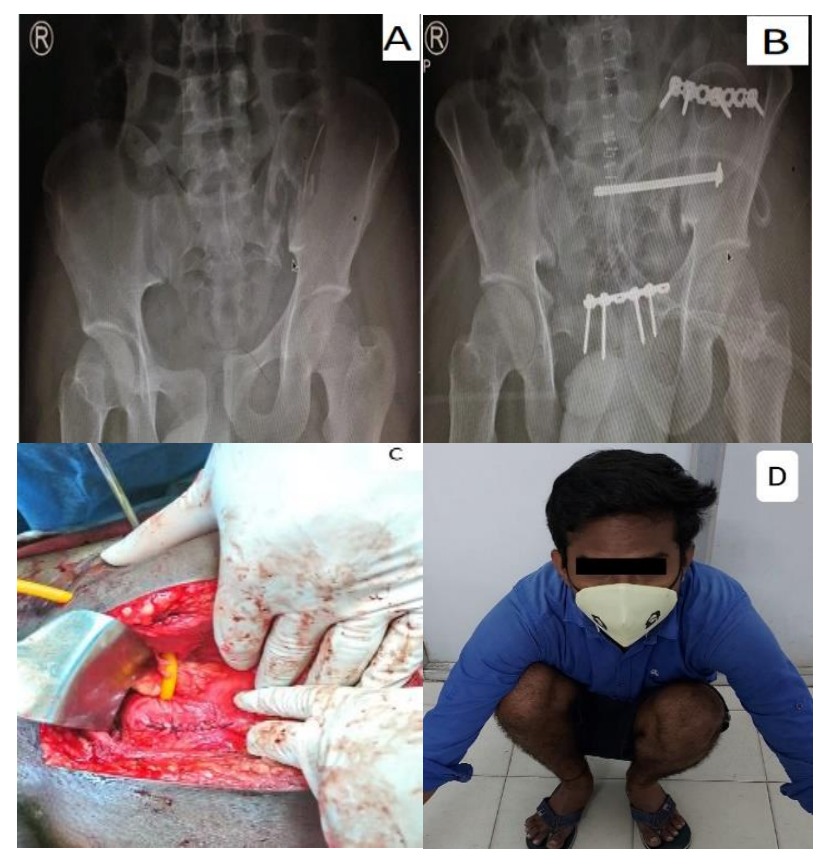

Figure 2 (A-D): An example of 26-year-old motor vehicle injury who sustained a pelvic fracture with associated urinary bladder injury. Preoperative radiograph, immediate postoperative radiograph, intraoperative picture shows repair of urinary bladder and $12^{\text {th }}$ month clinical picture of patient with excellent Majeed pelvic score.
Table 3: Functional assessment scoring at $12^{\text {th }}$ month follow-up.

\begin{tabular}{|lll|}
\hline \begin{tabular}{|l} 
Fracture type \\
Majeed score
\end{tabular} & $\begin{array}{l}\text { Tile type B, } \\
\text { n }(\%)\end{array}$ & $\begin{array}{l}\text { Tile type C, } \\
\text { n }(\%)\end{array}$ \\
\hline Excellent $(>85)$ & $8(72)$ & $5(55.6)$ \\
\hline Good $(70-84)$ & $3(28)$ & $4(44.4)$ \\
\hline Hannover score $($ HASPOC) & \\
\hline Very good & $4(36.4)$ & $2(22.2)$ \\
\hline Good & $7(63.6)$ & $7(77.8)$ \\
\hline
\end{tabular}

Table 4: Complications associated with management.

\begin{tabular}{|c|c|}
\hline Complications & $\mathbf{N}(\%)$ \\
\hline Sexual dysfunction & $7(35)$ \\
\hline Chronic pain & $7(35)$ \\
\hline Infection & $4(20)$ \\
\hline Neurological deficit & $1(05)$ \\
\hline Non-union & $2(10)$ \\
\hline
\end{tabular}

\section{DISCUSSION}

Management of complex pelvic injury is challenging to trauma team. In this study road traffic accident is leading cause followed by fall from height. Majority of patients belong to young age group. The main goals of management were control of bleeding, hemodynamic stabilisation and maintain the stability and integrity of the pelvic ring. ${ }^{10}$ Management of these injuries with E-FAST protocol helps in diagnosis of open pelvic fracture (pubic sympysis widening $>25 \mathrm{~mm}$ ), assessment of hemodynamic stability and early decision making in emergency room. ${ }^{6}$ The unstable pelvic fracture facilitates adequate space for haemorrhage and compromises the tamponade effect of intra pelvic and retroperitoneal organs which further increases the bleeding. Hence early realignment and proper anatomical restoration of pelvic ring by surgical fixation is essential. ${ }^{11}$ Traditionally the external fixators were commonly used to stabilize the pelvic ring but it carries risks like pin tract infection, injury to lateral femoral cutaneous nerve and pin loosening. ${ }^{12,13}$

With evolution in management protocol of these fractures, studies shows good outcome with early internal fixation of fractures. It provides direct fracture reduction with superior biomechanical stability and allows early mobilization. ${ }^{14}$ In our study, the overall functional outcome (Majeed and Hannover score) was satisfactory after internal fixation in complex pelvic fracture. The tile type B fracture patients had slight better outcome than type $\mathrm{C}$ fracture patients. However, we didn't find any significant correlation between type of Tile classification and the functional score. Similar study done by Ismail et al reported excellent Majeed score in $78.6 \%$ of tile type B and $50 \%$ tile type $\mathrm{C}$ cases and good Hannover score in $53.3 \%$ type $\mathrm{B}$ cases and $72.7 \%$ type $\mathrm{C}$ cases. ${ }^{1}$ Mardanpour et al reported $66 \%$ of tile type B patients had excellent and $15 \%$ patients had good Majeed score, while for tile type $\mathrm{C}$ 
patients, $46 \%$ patients had excellent and $27 \%$ patients had good Majeed score. ${ }^{15}$

Most common soft tissue injuries include urogenital structure, rectum, sigmoid, lumbosacral plexus, and retroperitoneal vessels. In this study $45 \%$ of patients had urogenital injury. These structures usually get injured due to sharp fractured bony end. Early diagnosis and management of associated soft tissue injuries is utmost important in complex pelvic fracture management to achieve good outcome. ${ }^{4,15}$

Even after good management complex pelvic fracture are associated with high rate of short term and long-term complications. Sexual dysfunction was common complication in complex pelvic fractures. Studies have shown that morbidity due to sexual dysfunction can reach up to around $60 \%$ of complex pelvic fracture cases. ${ }^{16-18}$ The combination of vascular, neurogenic and psychological trauma majorly influences this complication. In our study overall incidence of sexual dysfunction was $35 \%$ and all of them were male patients. Most commonly sexual dysfunction occurred in patients with associated pubic rami fracture or pubic diastasis as a component of complex pelvic fracture. It's probably due to abnormal stretching or injury to prostatic urethra and injury to neurovascular bundles of cavernosal bodies. ${ }^{17,19}$

Chronic pain is another major complication in complex pelvic fractures that compromises the patient's quality of life. ${ }^{20,21} \mathrm{We}$ found that type $\mathrm{C}$ fractures had a statistically significant co-relation with chronic pain $(p=0.016)$. It was mostly due to sacroiliac joint pain, nerve lesion, nonunion, malunion and limb length discrepancy. ${ }^{22}$

Infection was devastating complication in pelvic injury. Factors like open fracture, injury to bowel, urogenital injury and subcutaneous soft tissue trauma (MorelLavellee lesion) increases chance of infection. In present study four patients $(20 \%)$ developed superficial surgical site infection and all of them were managed with intravenous antibiotic therapy. Ismail et al also reported infection rate of $19 \%$ which is almost similar to our study. ${ }^{1}$

Limitation of our study includes small sample size and retrospective nature. Thus, study with large sample size and the higher statistical power required to validate our data.

\section{CONCLUSION}

Early definitive fixation of complex pelvic fractures had shown very good clinical and functional outcomes. Tile type $\mathrm{C}$ fractures have preponderance of landing the patient in chronic pain. Sexual dysfunction was common complication associated with complex pelvic fractures, especially in males. Its incidence was significantly related to pubic rami fracture or pubic diastasis and urogenital injuries.
Funding: No funding sources

Conflict of interest: None declared

Ethical approval: The study was approved by the institutional ethics committee

\section{REFERENCES}

1. Ismail HD, Lubis MF, Djaja YP. The Outcome of Complex Pelvic Fracture after Internal Fixation Surgery. Malays Orthop J. 2016;10(1):16-21.

2. Ghosh S, Aggarwal S, Kumar V, Patel S, Kumar P. Epidemiology of pelvic fractures in adults: Our experience at a tertiary hospital. Chinese journal of traumatology. 2019 Jun 1;22(3):138-41.

3. Coccolini F, Stahel PF, Montori G, Biffl W, Horer TM, Catena $F$ et al. Pelvic trauma: WSES classification and guidelines. World $\mathrm{J}$ Emergency Surg. 2017;12.1:1-18.

4. Schmal H, Markmiller M, Mehlhorn AT, Sudkamp NP. Epidemiology and outcome of complex pelvic injury. Acta Orthop Belg. 2005;71(1):41-7.

5. O'Sullivan RE, White TO, Keating JF. Major pelvic fractures: identification of patients at high risk. J Bone Joint Surg. 2005;87-B(4):530-3.

6. Incagnoli P, Puidupin A, Ausset S, Beregi JP, Bessereau J, Bobbia X et al. Early management of severe pelvic injury (first 24 hours). Anaesth Critical Care Pain Med. 2019;38(2):199-207.

7. Tile M. Acute Pelvic Fractures: II. Principles of Management. J Am Acad Orthop Surg. 1996;4(3):152s61.

8. Majeed SA. Grading the outcome of pelvic fractures. J Bone Joint Surg. 1989;71-B(2):304-6.

9. Dienstknecht $\mathrm{T}$. The long-term clinical outcome after pelvic ring injuries. Bone Joint J. 2013;95(4):548-53.

10. Hak DJ, Smith WR, Suzuki T. Management of haemorrhage in life-threatening pelvic fracture. J Am Acad Orthop Surg. 2009;17(7):447-57.

11. Grimm MR, Vrahas MS, Thomas KA. Pressurevolume characteristics of the intact and disrupted pelvic retroperitoneum. J Trauma Acute Care Surg. 1998;44(3):454-9.

12. McDonald C, Firoozabadi R, Routt ML Jr, Kleweno C. Complications Associated with Pelvic External Fixation. Orthopedics. 2017;40(6):e959-63.

13. Lindahl J, Hirvensalo E, Böstman O, Santavirta S. Failure of reduction with an external fixator in the management of pelvic ring injuries: long-term evaluation of 110 patients. J Bone Joint Surg Brit Vol. 1999;81(6):955-62.

14. Halawi MJ. Pelvic ring injuries: Surgical management and long-term outcomes. J Clin Orthop Trauma. 2016;7(1):1-6.

15. Mardanpour K, Rahbar M. The outcome of surgically treated traumatic unstable pelvic fractures by open reduction and internal fixation. $\mathrm{J}$ Inj Violence Res. 2013;5(2):77-83.

16. Vallier HA, Cureton BA, Schubeck D. Pelvic ring injury is associated with sexual dysfunction in women. J Orthop Trauma. 2012;26(5):308-13. 
17. Harwood PJ, Grotz M, Eardley I, Giannoudis PV. Erectile dysfunction after fracture of the pelvis. J Bone Joint Surg Bri Vol. 2005;87(3):281-90.

18. Metze M, Tiemann AH, Josten C. Male sexual dysfunction after pelvic fracture. J Trauma Acute Care Surg. 2007;63(2):394-01.

19. Shenfeld OZ. The incidence and causes of erectile dysfunction after pelvic fractures associated with posterior urethral disruption. J Urol. 2003;169(6):2173-6.

20. Kabak S, Halici M, Tuncel M, Avsarogullari L, Baktir A, Basturk M. Functional outcome of open reduction and internal fixation for completely unstable pelvic ring fractures (type C): a report of 40 cases. J Orthop Trauma. 2003;17(8):555-62.

21. Gerbershagen, Jürgen H. Chronic pain and disability after pelvic and acetabular fractures-assessment with the Mainz Pain Staging System. J Trauma Acute Care Surg. 2010;69(1):128-36.

22. Ramesh SK, Veerappa LA. Outcome analysis of pelvic ring fractures. Indian J Orthop. 2010;44:79-83.

Cite this article as: Kimmatkar N, Kantharaju H. The early definitive internal fixation of complex pelvic fracture and its outcome: our experience in level 1 trauma care centre. Int J Res Orthop 2022;8:183-7. 